\title{
Wood Tracking Information Systems to Confront Illegal Logging
}

\author{
Ioakeim K. Tzoulis ${ }^{1}$, Zacharoula S. Andreopoulou ${ }^{2}$, Elias Voulgaridis ${ }^{3}$
}

\section{N F O}

Received 29 Jan. 2014

Accepted 16 Apr. 2014

Available on-line 10 July. 2014

Responsible Editor: K. Rajkai

\section{Keywords:}

Information systems, Wood, tracking, traceability, illegal logging, Greek Forest.

\begin{abstract}
$\underline{\text { A B S T R A C T }}$
This paper examines the current wood tracking information systems used in international wood trade aiming to prevent and control illegally logged timber and wood products trade. Moreover, innovative log tracking mechanisms and technologies are also described and assessed. Wood tracking can add value to the wood product, by establishing an information system aiming to recognize and locate legal wood and wood products. Apart from the traditional punching and painting log-tracing methods, there are various digital wood traceability information systems for recognition, log tracking and monitoring, including barcodes, QR codes, RFID, microchips etc. Furthermore, various innovative wood tracking systems are also presented and discussed. The aim of the paper is to describe and quote those methods used in wood trade sector, to identify current trends and perspectives and to quote them as to their reliability, practicality, level of information provided and cost. Further it provides insight from log-traceability methods used in Greek Forests.
\end{abstract}

\section{Introduction}

Currently, the governance of natural resources has to face the increased diversity of connections between different environmental characteristics and decisions of local, regional, national, and international relevance, with high coordination and exchange between administrations and actors across the public/private and the expert/stakeholder divide (Andreopoulou et al., 2011). In the end of the $20^{\text {th }}$ century, Non-Governmental Organization (NGO) initially became aware of illegal logging and the ecological impact of illegal forest harvesting and forest deforestation (Tacconi, 2007). Following the global forest governance identified the need to ensure timber legality in international wood trade sector, especially as trade in illegally logged timber along with forest illegal activities is a major problem for many timber-producing countries (Brack, 2005, Cashore and Stone, 2012). Illegal logging refers to a range of illegal activities related to forest ecosystems, forest industries and timber and nontimber forest products (Tacconi, 2007). In the first place, within the context of global environmental concerns it became acknowledged that illegal logging and related trade is a daily practice in many timber-producing countries and contributes towards forest degradation (Brack, 2003, Wiersum et.al., 2013). It is clear that several enterprises, in developed and developing countries, benefit from significant profits arising from illegal activities (Brack et.al., 2002, Brack, 2003). The initial step in controlling the international timber trade is the establishment of a digital system to identify legally produced $\operatorname{logs}$ and wood products. Information Communication Technologies (ICT) can be used within environmental governance in the interest of the natural environment and the natural resources regarding sustainability (Andreopoulou, 2013).

\footnotetext{
${ }^{1}$ loakeim K. Tzoulis

Aristotle University Of Thessaloniki, Greece

itzoulis@for.auth.gr

${ }^{2}$ Zacharoula S. Andreopoulou

Aristotle University Of Thessaloniki, Greece

randreop@for.auth.gr

${ }^{3}$ Elias Voulgaridis

Aristotle University Of Thessaloniki, Greece

evoulga@for.auth.gr
}

ISSN 2061-862X (http://www.magisz.org/journal)

Ioakeim K. Tzoulis, Zacharoula S. Andreopoulou, Elias Voulgaridis: Wood Tracking Information Systems To Confront

Illegal Logging 
The ability to perform and track the whole follow-up of products in industries is accomplished by implementing systems of automatic identification, which are capable to create a link between the product, the database of the product and its process. Tracking mechanisms are further complex by the composition of individual wood products and shipments of timber, which in general contains an extensive range of logs and processed products, with different species and sizes (Tzoulis and Andreopoulou, 2013).

Traceability information systems consist of processes to maintain records that expose the trace of a particular input from suppliers to final customers (Daff, 2007). Under EU law, "traceability" means the capability to track any product, throughout all phases of production, processing and distribution. This track refers to the recording through means of barcodes, RFID tags, QR codes and other tracking methods (EU, 2007). The elemental characteristics of traceability systems are: a) identification of units/batches of all inputs (Product traceability information), b) lot identification of processed product (Production records and batch labeling), c) information on when and where they are moved and/or transformed (Documentation) and d) a system linking this data (Reconciles product to documentation). Emerging traceability technologies function as a means for communication, making information accessible along the supply chain, thus deficient management among these links creates a crack in the information chain and a consequent loss of traceability (Tzoulis and Andreopoulou, 2013). A supportive traceability system relies on being able to track product one step forward and one step back at any point in the supply chain. There are reviews about key traceability technologies, such as DNA markers, electronic tagging, ways of storing and transmitting traceability data and the range of data carrier technologies in various studies their decisive factors (Ramesh, 1998), the need for verifiable traceability (Opara, 2003), the role of traceability systems not only in ensuring safety and combat fraud but in optimizing business performance along with novel techniques description (Smith and Furness, 2006, Bechini et.al., 2008, Mousavi et.al., 2005).

\subsection{Wood Traceability/Tracking systems in Wood Trade}

Forests offer an extensive variety of services to humans, including wood products, recreational opportunities and ecosystems services. Just about half of the wood products harvested for human use worldwide are used for fuel wood and the other half for industrial purposes such as furniture, building materials or paper products. Forest products are significant components of international trade. Processed products have developed in importance as a proportion of total wood product exports, and numerous countries have as well seen increasing production and export of secondary processed wood products, including wooden furniture, builders woodwork (doors, window frames, flooring, etc.) and a range of small products (tools, brooms, boxes, etc.) (Bourke and Leitch, 2000).

Each system designed to control illegal timber trade requires harvested logs to be identified, inspected and documented, and then followed through processing and packaging to export with subsequent cross-checking with cooperating importers. The aim of wood traceability is to prevent the movement of illegal timber, and to explore ways in which the export and import of illegally harvested timber can be eliminated, including the possibility of a former notification system for commercially traded timber. By establishing an information system to avert illegal products, value is added to the product (FAO, 2002)

A chain of custody estimation is necessary in following this process and revealing whether illegal timber is entering legal commerce during harvesting, processing or at the point of export. (Bourke and Leitch, 2000, Brack, 2005). Various wood tracking technologies for tracking logs from the forest to the mill have been already described and they vary from simple painting methods to bar coded labels, mechanised coding systems, and radio-frequency identification transceivers (Brack et.al., 2002, Dykstra et.al., 2003, Tzoulis and Andreopoulou, 2013).

The worldwide traded timber should come from sustainable managed forests. Two certification systems of sustainable forest management have been developed: a) FSC: Forest Stewardship Council and b) PEFC: Programme for the Endorsement of Forest Certification schemes (ACE UK, 2012). A nation can trade in round wood and export paper produced, and the relevant information is where the wood was grown, as a traceability application. This information is then used to trace the origin of main 
products behind consumed products along international supply chain (Kastner et.al., 2011). Wood traceability information systems make sure that wood derives from sustainable sources and supply a successful technique to fight illegal logging. These Information systems cover data on the source and movement of wood throughout harvesting area until its final destination. It is important to acheive detailed tracking of the log production and movement of timber and wood products aiming to guarantee the legality of the product (Brack, 2003).

It is important that wood for trade should not arrive a) from illegal cuttings, b) areas of natural value, c) gene-modified trees, d) areas with social conflicts, e) natural forests transformed to other use (Korsnas, 2012). In the wood industries, the achievement of common identification and information systems used in other industries presents implantation problems, mostly because of the nature of wood and the particular features of the manufacturing process. It is highly acknowledged that wood presents high changeability in its structure and features such as knots and cross grain can be found in different degrees in wood As a result the exceptionally changeable nature of wood helps the existence of exclusive characteristics that can be used as a model of recognition (Charpentier and Choffel, 2003). However, traceability information systems of high technology require additional costs (Brown, 1997). If an effective legal information tracking system can be developed and became obligatory across an entire country, then illegal timber can be defined as any timber that is not included in that system and exists outside. Nevertheless, it is more likely that such an information system would initially develop, on a voluntary and pilot basis, probably in certain countries and certainly in a non-universal basis, with timber not covered by the system simply being of 'unknown legality', not positively identified as legal, but not automatically illegal.

Wood entrepreneurship gains an increasing interest, globally given the current trends in the modern society in wood and wood products because wood is the raw material for different industrial products of primary processing such as poles, sawn timber, veneer, plywood, particleboard, fiber boards, pulpwood, etc., which are materials to produce other products such as secondary treatment furniture and paper (Tzoulis et.al., 2013)

The aim of the paper is to study the emerging traceability technologies and tracking information systems used in wood trade sector in order to fight illegal logging and trade and in that way to add value to the product itself. This would be beneficial both for companies and the consumers, and of course the trade between countries, providing better quality for wood and its products, from legal sources. There will be presented the features and feedback for every method assessing reliability, practicality, cost and level of information provided. Further insight from the contemporary log tracking system for the case of the University Forest of Pertouli, in Greece, will be presented.

\section{Methodology}

Initially, various systems of wood traceability and other tracking systems used as implements for quality wood trade, in order to fight illegal logging and add value and reliability to the commodity will be identified, registered and studied. For the identification and registration of the tracking systems, a literature review has been performed in relative studies and research (Choffel, 1999, Brack et.al., 2002, Brack, 2003, Charpentier, 2003, Dykstra et.al., 2003, Johansson et.al., 2003, Mousavi et.al., 2005, Brack, 2005, Fuentealba, 2006, Smith and Furness, 2006, Bechini et.al., 2008, Niblaeus, 2009, Lyne, 2009, Ntalos et.al., 2010, Water, 2012, Hansen, 2012, Varallyai, 2013, Tzoulis and Andreopoulou, 2013) and relative sources in the Internet (IK EU, 2010, GIZ, 2010, FSANZ, 2012, Adazon, 2013). There is a discussion for traceability technologies for log tracking and monitoring are qualitatively criteria such as their reliability, practicality, cost and level of information.

Aiming to have insight from the contemporary log tracking system in Greece, a field study was carried out during summer of 2013 in University Forest Pertouli, in Central Greece.

\section{Results}

The main types of wood traceability that were retrieved are: Punching/Brand hammers, Marking Logs With Paint/Chemical tracer paint, Barcodes/Bar-coded tags and scanners, QR Codes, DNA Fingerprinting, RFID Transponders, The French CIRAD-Foret system, Microtaggant tracer Paint and 
microscopes, Satellite-borne sensors, Unique Reflector Identifiers, Ground video surveillance cameras and automatic activation devices.

\subsubsection{Punching/Brand hammers}

All those methods of wood tracking systems that constitute technical means of wood identification and $\log$ tracking mechanisms are presented with information for their reliability, practicality, cost and level of information. It is a plain and low-cost method where the logs' ends are punched with a hammer and it requires a minimum training level. Marking logs with a hammer is a plain technology and is the oldest method to point out ownership or considered use of the log. It's a practical method, quick and easy to apply in cut trees only, but with low security and reliability as it is very easy to make copies of the punchers. This method verifies a huge quantity of symbols, usually locally identified. Nevertheless, for comprehensive traceability, a unique cipher is used, representing a code that is applied to the log automatically in the harvester head. This code can be connected with trade and physical data about the log, stored in a database. Even though punching can be detected by a camera and a vision system, environmental difficulties such as mud and ice can disturb successful reading (Niblaeus, 2009).

\subsubsection{Chemical Paint Marking}

Marking logs with paint, where the color is the code, is one of the oldest and also low cost methods (Dukstra et.al. 2003). The marking can be completed automatically or by hand and is comparable to punching. Medium in reliability, it provides information, not log origin. Can give false readings if paint degrades or reacts similarly there are problems in marking with paint in wet log-end, with snow and mud and change of color. It is practical as there is no need for specific training. The aim is to find a cost-efficient solution. For this reason LNP (Luminescent Nano Particles) is used. These nano particles are added to the fluid paint, that becomes unseen in regular light, but when illuminated by a laser it becomes visible. The major advantage is the enlarged frequency range and the detail that the wavelengths can be alienated with high accuracy, meaning further unique identities. Additional significant findings are that LNP is more insolent to snow and mud and it is more difficult to fake (IK EU, 2010).

\subsubsection{Barcodes}

Barcodes have become a regular part of modern life, adopted in international trade and nearly all products contain a barcode on it, it dominated the market for 40 years (Varallyai, 2013). The barcode consists of a machine-readable code in the form of numbers and a pattern of parallel lines of varying widths, which is printed on an item or product. It's a practical method with a good reliability and security level. Following, an optical reader or scanner picks up the barcode translate the information included, such as production location, production date, transportation details, entrepreneurs name, etc aiming to further control wood stock (Oxford dictionaries, 2013). The barcode traceability system is plain and low cost while it is difficult to be massively applied in wood trade and wood traceability, because of wood texture. Still, there are several barcode wood traceability applications, using plastic or metal labels with printed barcodes to maintain track of logged trees. As soon as the tree is cut, workers use a handheld barcode scanner to scan processing and export data into a database (Adazon, 2013).

\subsubsection{QR Codes}

QR code, which is short for "Quick Response" code), is a two-dimensional barcode that can be read using a QR barcode reader, camera or smart phone application. It is called a 2D barcode since a QR code is capable to carry information both in vertical and horizontal direction and it expands dramatically the data storage capability compared to simple barcodes. The QR Code is initially appeared in Japan where is widely used. It is a registered trademark of Denso Wave Inc. in Japan and it is now used in many countries (Lyne, 2009). Furthermore QR Codes can be printed and displayed in all places. The extended use of smart phones with QR reader application have made QR codes a common tool because they carry information, explanations and details of all kind, for consumers when 
applied in commodities, for visitors in culture areas, for science, entertainment, etc. It can also be used online (Waters, 2012). Even though the fact that originally was used to trail parts in vehicle manufacturing, QR Codes are now used over a group of applications, such as logs and generally in the field of environment and agriculture. Numerous fields in the agriculture are covered by QR codes (Hansen, 2012). By adding a QR Code near price tags, it can provide potential information to customers such as allergy information, preparation tips, directly. The most considerable objective in most cases is the traceability or monitoring of the system. In that way QR codes could be incredibly useful to the "chain of industry" in wood, for not only the source of the wood but also its technical facts (Waters, 2012). In the case of wood traceability, a QR code can be marked in a tree log by laser (Tzoulis and Andreopoulou, 2013).

\subsubsection{DNA Fingerprinting}

New experimental methods in research level have been offered in order to avoid fraud and other illegal activities in tracing logs. That log tracking method is based on annual rings which are unique for each tree and are further recorded in database with samples. The genetic composition of tree populations shows a spatial model, meaning that the timber origin can be detected and controlled by comparing the genotypes of wood samples with the genetic pattern observed in sampled populations, providing a wood DNA. It is a reliable method, as DNA cannot be faked (Smith and Burgess, 2006). These types of log tracking methods are not practical as they presuppose the existence of an adequate database, they are high-cost to establish and high-level specialist training is also needed. However, it is a reliable and secure method as it provides a high level of information.

In the other case of isotopic fingerprinting, isotopes differ in their specific masses. Diverse chemical elements are taken by the plants through water, nutrition from soil and by photosynthesis. The distribution of isotopes shows different patterns and by combining these patterns of different elements it is achievable to check the declaration of origin (GIZ, 2010).

Micro-wave sensor tracing technology is based on the use of a micro-wave sensor, that allows to acquire an internal mark of the wood products, initially used for finding wood features such as knots, cross grain (Charpentier, 2003) and mechanical characteristics of wood (Choffel, 1999). Microwaves act together with the material according to its dielectric properties (Fuentealba, 2006). The transmission of this type of waves through the wood is mainly influenced by the moisture content and the existence of features such as knots and cross grain, which are more changeable from one board to another, used for the automatic identification. The product circulates between the emitter and receivers, and then its mark is digitized on a computer (Johansson et.al. 2003).

\subsubsection{RFID (Radio-Frequency Identification) tags}

This is a high reliability and accuracy method (Mousavi et.al. 2005). The RFID tag is extremely small and can be affixed to an object and used to track and manage inventory, assets, wood, etc. (Várallyai, 2013). Radio Frequency Identity (RFID) tags can be planted inside a wood log and transmit data to receivers. These RFID tags can be read-only or read-write, and can be programmed in the field or in advance. They are passive; they only transmit data when become 'excited' by a signal from the RFID reader. These tags are very durable, they can live up to 8 years, they can be reprogrammed and they can be read under water. Aiming to automatic identification and tracking, radio-frequency identification (RFID) uses a wireless non-contact system with radio-frequency electromagnetic fields for data transmission from a tag, in a product (Mousavi et.al. 2005). There is comprehensively literature about RFID technology reviewed in recent research (Várallyai, 2013), where it is studied the use of RFID aiming to improve supply chain and inventory operations. RFIDs are simple to hide or fit in other items due to its small size. The RFID technology is the most promising method for marking logs at this moment, as, unlike barcodes technology, RFID allows acquiring information at a rate of 1000 tags per second and it is expected a growing acceptance of RFID technologies in the next years as basic components within traceability information systems (Bechini et.al., 2008). The readability in the real-life tests and demonstrations was close to $100 \%$. Apart from the technical performance RFID represents a sophisticated technology that opens up for new business applications. A further advantage compared to other methods is that it is not easy to deceive (Dykstra et.al. 2003). Still there is a need for further development of this technology. The 
automatic application must be very tough with a minimum of production disturbances. The current trend is positive for the RFID technology and generally the cost per tag is expected to decrease (FSANZ, 2012). Traceability in wood packaging material can be secured with the suitable thermal handling, as the technology of radio gives today adequate solutions. Apart from the simple thermal handling in wooden packaging material, other information can be stored on the same label such as quantity and origin of wood (Ntalos et.al. 2010). The cost of the method is now high but it still decreases.

\subsubsection{Innovative methods}

Various innovative methods have been proposed in international level and other are still under research (Brack et.al. 2002)

\section{a) The French CIRAD-Foret system}

It is a low-cost and plain method of timber tracking in which the average diameters of the two ends and length of the log are recorded and a sketch is made of the growth rings at two ends and other characteristic features (e.g. knots, bolls, bends etc.). Each log has serial number matching form. The form contains all the necessary information but cross-checking and auditing is required.

It is a reliable method as counterfeit proof documentation and cross-comparison of records among felling and processing should make it difficult to substitute logs into the system. With this method counterfeit forms and hammer marks can get through checkpoints but will be detected by audit. The method is practically easy to learn and use forest management consultancy development alternatives' recent Log Monitoring and Log Control project in Cambodia noted that the CIRAD system has 'a proven track record under extremely difficult conditions and is known to international timber concessionaires', it is also used in Thailand and Laos (Brack et.al., 2002).Microtaggants are microscopic particles

It is a high-cost method with very high reliability, high level of information and it is virtually impossible to counterfeit. These particles are composed of layers of different colored plastics; millions of permutations are possible by combining several colors in different sequences. The coding sequences are then read with an x100 pocket microscope. It is the fastest marking technique and it is easy to apply with spray gun. The disadvantages are that it can be difficult to read in field, wet or muddy logs may not take marker well while installation costs are high. Furthermore operating costs for that method are kept low while it provides a very high level of information

c) Automatic cameras and remote sensing

Automatic cameras in satellites are used along with remote sensing techniques. This innovative method provides high level of information over a large scale while it is a high cost technique, but for a large amount of information. This method is not practical for monitoring movements for individual logs but provides valuable information across concessions and nationally.Automatic cameras and remote sensing are clearly large-scale technologies that are not designed to measure individual logs but areas of action and summative volumes of traffic, etc. For example in December 1999, NASA launched two environmental satellites (LANDSAT 7 and EOS TERRA) that should allow custom production of accurate forest maps and monitoring of many aspects of concession management and make sure the veracity of protected areas.

\section{d) Reflectors}

Reflectors are read by laser devices and may possibly be of value to aerial surveillance teams trying to spot concession boundaries, log trucks carrying illegal loads and the like, on the other hand satellitebased sensors can be read over enormous distances but are currently relatively weighty. Until now, technological developments in forest management have tended to go before policy rather than being driven by it. Even though the massive role for new information technologies, such systems will only be invented if policy needs for their use are clearly identified. Reading is fast and accurate and can be achieved remotely, from air, etc. The method provides very good reliability and security, it is a continually improving method but it is poor in practicality. It's a high cost method but the level of information is low while it can be modified to incorporate memory cards and unique identifiers. 


\section{e) Ground Video Surveillance Cameras and Automatic Activation Devices}

Ground Video Surveillance Cameras and Automatic Activation Devices are used for log tracking. The reliability of the method is good as the signal can be transmitted remotely to enforcement personnel. It is not a practical system for monitoring movements of individual logs but good for monitoring major transportation routes. It can be activated by light-, by sound- or by motiondetectors. High-level information can be collected but it is a very high cost method (Brack et.al. 2002).

\subsection{The case of wood tracking in Greece}

In Greece until 1986 a government organization, named State Forests Exploitation (SFT), was used to function in order to manage and distribute wood and its products. Today, both State and Private individuals have access to wood trade. The University Forest in Pertouli, Trikala, in Central Greece is a public forest estate. It is located in the Pindos Mountain Range, and extends from the western slopes of Koziakas Mt. to the north-eastern slopes of Boudoura Mt. at an altitude of about 3,608.92 to 5,577.42 feet (latitude $39^{\circ} 32^{\prime}-39^{\circ} 35^{\prime}$ and longitude $21^{\circ} 33^{\prime}-21^{\circ} 38^{\prime}$ ). It covers an area of $3,296.59$ hectares, of which $2,361.83$ hectares are wooded or partly wooded mostly with fir and pine trees, 168.22 hectares of bare and barren land, 583.71 hectares of mountain grassland, 114.00 hectares of flat grassland and 68.83 hectares of other types of land, such as fields, settlements, etc. Self-seeded hybrid fir trees dominate the area of the University Forest of Pertouli. There are also small clumps of beech trees, oak trees, maple trees, ostrya trees, juniper trees, cedar trees, lime trees, willow trees, etc. Black, scotch and leucodermis pine trees, spruce trees and thuja trees have been planted in the forest as well (AUTH, 2013). In order to manage the forest properly, the area is orographically structured and divided into 9 zones (Braiko, Vathi, Koromilia, Calderimi, Lyxa, Koziakas, Viga, Liopeika and Glapatsa). Forest products include pine round logs with intact bark or without bark (up to two meters long), round timber (two meters long), as well as firewood. A number of measures are taken to protect the forest, while one of the goals set is to achieve maximum sustainable yield and the contemporary mechanism used in the University Forest for wood tracking, as in all Greek forests is similar to punching.

Regarding the log-tracking system, a small metallic placket is set firmly on the wood log immediately after wood logging in the forest area. The placket signs and marks each specific wood $\log$. With the following information concerning wood logs, such as quality of log, quantity of log and logging date information, etc. All these information are also registered electronically in digital forms and verified by Forest Service. Thus, these records are preserved in digital files that are kept and verified through the Local Forest Unit for further trade of wood to entrepreneurs. These records will follow wood logs till their initial exploitation in industry.

\section{Conclusions}

This paper has examined the physical constraints of establishing an information system to track legally produced logs and wood products. However, such a tracking information system can only work successfully if there is sufficient funding and political will. Aiming to guarantee legal wood in the market, it is necessary to establish a comprehensive universal monitoring of every stage of the chain of production, processing, transport, export and import of wood. There are many alternative-tracking options besides to the traditional system based on keeping paper records respective to punching and painting tracing. Within digitalization era, there are computer-based information systems for recognition, traceability, log tracking and monitoring, including barcodes, QR codes, RFID, microchips etc. The quoted and described wood traceability and log tracking methods vary in their practicality and reliability. Innovative log-tracking mechanisms, such as DNA fingerprinting and satellite surveillance tend to be high cost and difficult to apply. Older and widely applied methods, such as paint marking, punching and barcodes continue to exist and are effectively employed in wood supply chain. It is important that greater efforts need to be made in improving international collaboration on wood tracking data exchange within a global wood traceability information system with unique standards and features.

\section{References}

ISSN 2061-862X (http://www.magisz.org/journal) 
ACE UK. 2012. Natural and renewable, traceability. http://www.ace-uk.co.uk/natural/traceability.

Adazon. 2013. Using Barcodes in the Lumber Industry. http://www.adazonusa.com/blog/uncategorized/usingbarcodes-in-the-lumber-industry.

Andreopoulou, Z.S., B. Manos, N. Polman and D. Viaggi. 2011. Agricultural and Environmental Informatics, Governance, and Management: Emerging Research Applications. IGIGlobal. USA

Andreopoulou, Z. 2013. Green Informatics: ICT for Green and Sustainability. Journal of Agricultural Informatics. 3(2):1-8.

AUTH. 2013. University Forest of Pertouli. Aristotle University Forest. http://www.auth.gr/en/units/8166

Bechini, A., Cimino, M. G., Marcelloni, F., \& Tomasi, A. 2008. Patterns and technologies for enabling supply chain traceability through collaborative e-business. Information and Software Technology, 50(4): 342-359.

Bourke I.J and Leitch J. 2000. Trade Restrictions and their Impact on International Trade in Forest Products (Rome: FAO).

Brack D., Gray K., Hayman G. 2002. Controlling The International Trade In Illegally Logged Timber And Wood Products. Sustainable Development Program. Royal Institute of International Affairs. http://www.abc.net.au/4corners/content/2002/timber_mafia/viewpoints/brack.pdf

Brack, D. (2003). Illegal logging and the illegal trade in forest and timber products. International Forestry Review, 5(3):195-198.

Brack, D. (2005). Controlling illegal logging and the trade in illegally harvested timber: the EU's Forest Law Enforcement, Governance and Trade Initiative.Review of European community \& international environmental law, 14(1): 28-38.

Brown S. 1997. Estimating Biomass and Biomass Change of Tropical Forests: A Primer. FAO, Rome, Italy.

Cashore B., Stone M.W, 2012. Can legality verification rescue global forest governance?: Analyzing the potential of public and private policy intersection to ameliorate forest challenges in Southeast Asia, Forest Policy and Economics, 18, May :13-22.

Charpentier P, Choffel D. 2003. "The feasibility of intrinsic signature identification for the traceability of pieces of wood", Forest Products Journal, 53 (9): 40-46.

Choffel D. 1999. Automation of wood mechanical grading-Couplingof vision and microwave devices.

Daff. 2007. http://www.daff.gov.au/_data/assets/pdf_file/0007/192787/traceability_eggs.pdf, January.

Dykstra, D. P., Kuru, G., Nussbaum, R. 2003. Technologies for log tracking. International Forestry Review, 5(3): 262-267.

EU. 2007. Directorate for health and consumer protection. Food traceability. Factsheet. http://ec.europa.eu/food/food/foodlaw/traceability/factsheet_trace_2007_en.pdf.

FSANZ. 2012. Why is traceability important. http://www.foodstandards.gov.au/scienceandeducation/factsheets/foodsafetyfactsheets/foodtraceability.cfm.

Fuentealba C, Choffel D, Charpentier P. 2006. Non destructive Control tool for wood traceability. In Workshop on non destructive testing of wood, Concepcion, Chili.

GIZ. 2010. Genetic and Isotopic fingerprinting methods-practical tools to verify the declared origin of wood. Documentation of international confernce, Eschborn 3-4 November 2010,http://www.pfbccbfp.org/docs/news/Fevrier Avril\%202011/GIZ_Conf_doc_Fingerprinting_2010_en_web.pdf.

Hansen J P. 2012. Using QR codes for context specific support around the farm. AFITA/WCCA 2012 Taipei/Taiwan 3-6 of September, p.1-5

IK EU. 2010. Final report INDISPUTABLE KEY EU Integrated Project of the Sixth Framework Programme, Priority 2, Information Society Technologies, $\mathrm{n}^{\circ}$ 34732: INDISPUTABLE KEY - Intelligent distributed process utilisation and blazing environmental key. Coordinator: Richard Uusijärvi, SP, Sweden http://interopvlab.eu/ei_public_deliverables/indisputable-key/D1\%2024\%20Final\%20Report.pdf.

Johansson J, Hagman O, Fjellner B A. 2003. Predicting moisture content and density distribution of Scots pine by microwave scanning of sawn timber. Journal of Wood Science, 49(4): 312-316.

ISSN 2061-862X (http://www.magisz.org/journal) 
Kastner T, Kastner M, Nonhebel S. 2011. Tracing distant environmental impacts of agricultural products from a consumer perspective. Ecological Economics 70:1032-1040.

Kollmann F, Côté W. 1968. “Principles of Wood Science and Technology”, Springer-Verlag.

Korsnas. 2012. Traceability of hood. http:/www.korsnas.com/fr/OmKorsnas/Forestry/Miljoarbetet/Traceability-of-wood/.

Lyne M. 2009. What is A QR Code And Why Do You Need One? Search Engine Land [Online]. Available at http://searchengineland.com/whatis-a-qr-code-and-why-do-you-needone-27588. Accessed 11/8/11

Mousavi, A., Sarhadi, M., Fawcett, S., Bowles, S., \& York, M. (2005). Tracking and traceability solution using a novel material handling system. Innovative Food Science \& Emerging Technologies, 6(1):91-105.

Niblaeus G. 2009. Presentation "Industrial breakthrough of new methods and technologies in the wood industry".

Ntalos G, Skarvelis M, Karampatzakis D. 2010. Tracing thermal treatment in wood using RFID. Proceedings of COST Action E53 Final Conference: "The Future of Quality Control for Wood \& Wood Products', Edinburgh. p. 7.

Opara, L. U. 2003. Traceability in agriculture and food supply chain: a review of basic concepts, technological implications, and future prospects. Journal of Food Agriculture and Environment, 1:101-106.

Oxford dictionaries. 2013. Barcode.http://oxforddictionaries.com/definition/english/barcode.

Ramesh, B. 1998. Factors influencing requirements traceability practice. Communications of the ACM, 41(12): $37-44$.

Smith, I., \& Furness, A. 2006. Improving traceability in food processing and distribution. Woodhead Publishing Ltd.

Tacconi, L. 2007. The problem of illegal logging. Illegal Logging: Law Enforcement, Livelihoods and Timber Trade, 1-16.

Tzoulis I, Andreopoulou Z, Koliouska C, Tsekouropoulos, G, Samathrakis V. 2013. «WooDB: A DBMS Approach as a Marketing Tool for Wood Entrepreneurship». Procedia-Technology, 2013, 8: 275-284

Tzoulis I., Andreopoulou Z. 2013. Emerging Traceability Technologies as a Tool for Quality Wood Trade. Procedia Technology, 2013, 8: 606-611

Várallyai L. 2013. From barcode to QR code applications. Journal of Agricultural Informatics, 3(2).

Waters J. 2012. QR Codes for Dummies - Portable Edition, Published by John Wiley and Sons Inc., Hoboken, New Jersey.

Wiersum K.F., Lescuyer G., Nketiah K.S., Wit M. 2013 , International forest governance regimes: Reconciling concerns on timber legality and forest-based livelihoods, Forest Policy and Economics, 32:1-5 